\title{
Using Vignettes to Conduct a Dynamic Value-based Approach to Advance Care Planning
}

\author{
Amberyce Ang ${ }^{1 *}$ and Loy Liang Meng ${ }^{2}$ \\ ${ }^{1}$ PhD candidate, Singapore University of Social Sciences, Singapore \\ ${ }^{2}$ Medical doctor at Tan Tock Seng Hospital, Singapore
}

Corresponding author: Amberyce Ang, PhD candidate, Singapore University of Social Sciences, Singapore

\section{ARTICLE INFO}

Received: 幽 October 09, 2020

Published: 慧 October 29, 2020

Citation: Amberyce Ang, Loy Liang Meng. Using Vignettes to Conduct a Dynamic Value-based Approach to Advance Care Planning. Biomed J Sci \& Tech Res 31(3)2020. BJSTR. MS.ID.005116.

keywords: Advance Care Planning; ACP; End-of-life; Palliative; Social-Cultural

\section{ABSTRACT}

A systematic literature review was conducted on Advanced Care Planning (ACP) to discern the factors which impeded its acceptance among the Singapore population. The key finding of this review is that Singaporeans have greater awareness of ACP, but social and cultural factors continue to hinder its acceptance by the Singapore population. Based on this finding, this study designed a set of vignettes to suss out the values that ACP decision could be based on. The administration of ACP could circumvent culturally sensitive issues by using a third-person perspective in the vignettes. The patient's preferences could also be more clearly stated in scenarios whereby there are competing interest e.g. the dilemma between personal preferences and burdening the family. This study highlights the importance of an ongoing discourse as the values of patients may change over time. The use of vignettes supplements existing ACP questions, facilitates ongoing ACP conversations, and creates opportunities to provide socio-emotional support for the patient.

Abbreviations: ACP: Advanced Care Planning; AMD: Advanced Medical Directive; MOH: Ministry of Health; AIC: Agency for Integrated Care; ACPEL: Advance Care Planning and End of Life Care; TTSH: Tan Tock Seng Hospital

\section{Introduction}

Advanced Care Planning (ACP) refers to a voluntary, non-legally binding discussion about future care plans between an individual, his healthcare providers and close family members, in the event that the individual becomes incapacitated and unable to make decisions. ACP may also include clarifications about the individual's wishes, values, and healthcare objectives. ACP does not only deal with end-of-life issues, but also applies to long-term care. ACP also includes the Advanced Medical Directive (AMD) and Lasting Power of Attorney [1,2]. In 2011 the Ministry of Health (MOH) Singapore, had appointed the Agency for Integrated Care (AIC) to coordinate the implementation of a national ACP program across different healthcare institutions [3]. Over the last few years, $\mathrm{MOH}$ has implemented a series of measures to raise public awareness of ACP and increase manpower in the palliative healthcare sector, which have led to a significant increase in the take-up rates for ACP $[3,4]$. Despite the increase in the take-up rate of ACP, these studies $[5,6]$ continued to highlight challenges which impede the initiation or completion of ACP by the Singapore population; some of these challenges are similar to those faced by Western societies, but there are challenges which are unique to Asian cultures.

Systematic reviews across countries highlighted that there are major knowledge gaps about ACP initiation, timeliness, optimal content, and impact because of narrow research focus and fragmented evidence $[5,6]$. Research should use a holistic evaluative approach that considers its intricate working mechanisms and the influence of systems and contexts. Systematic reviews $[7,8]$ on ACP across countries are available, however one of the issues is the inconsistencies in the types of instruments and the number of items used to assess knowledge of ACP. Thereby, this systematic review has chosen to focus on the Singapore context to understand unique factors that impeded initiation and conduct of ACP. Even though the application of ACP should be sensitive to cultural differences, the proposed dynamic value-based approach to ACP can be universal in application. The vignettes can be adapted to be context-specific 
and context-relevant. In the Asian context, discussion on death and dying may cause the family member to be mistaken as being unfilial i.e. avoiding the responsibility of caring for the old and aged [9]. The use of indirect communication approaches to determine the readiness of traditional Chinese seniors was recommended [10,11]. Faith-based values and interpretation of religious doctrines can influence patients' views and receptivity towards ACP [12].

In fact, it is suggested that religious leaders and even social workers and might be suitable candidates in influencing the views and receptivity of ACP $[13,14]$. There are challenges that impede the initiation of ACP discussions including physicians' apathy and inadequacy of training. Thus far there has been no systematic review about the ACP in Singapore, so our study seeks to review existing literature to discern the factors which impeded its acceptance among the Singapore population. More importantly, our study aimed to utilize the findings from this systematic literature review to design a dynamic principal-based approach to complement existing ACP questions. The objective of value-based approach is to overcome existing hindrances to the implementation and acceptance of ACP. Another objective of this approach is to allow patients and their family members to base end-of-life decisions on values instead of narrowly defined preferences for specific matters. This approach is also dynamic as it considers competing interests and dilemmas, to allow patients to prioritize their preferences. As existing ACP may not capture nuances and may not be sufficiently versatile in decision making when confronted with "shades of grey" [15-21], a value-based approach will also assist family members to make more informed decisions when faced with dilemmas or grey areas.

\section{Method}

An electronic search of the following databases: PsycINFO, PubMed, CINAHL, Google Scholar, SAGE Journals and Singapore Medical Journal, was carried out. We searched for research articles up till Sep 2020 and used the Boolean search criteria: "advance care planning" OR "advanced care planning") AND "Singapore". We included all study types in English which were carried out on the Singapore population (Figure1). In addition to the published studies, we also reviewed findings which were presented in posters and conferences so as to prevent publication bias (Table 1).

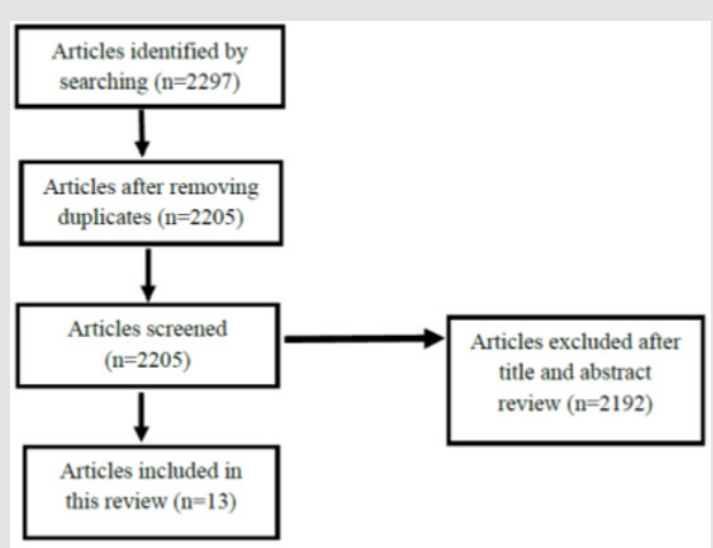

Figure 1: Flow Chart Showing Selection of Articles.

Table 1: Summary of Studies Included in this Review.

\begin{tabular}{|c|c|c|c|c|c|c|}
\hline Reference & Year & Study Type & Population Sampled & $\begin{array}{l}\text { Number of } \\
\text { subjects }\end{array}$ & Factors Identified & Notes \\
\hline Lee et al. [16] & 2018 & Survey & $\begin{array}{c}\text { Older adult patients } \\
\text { who had undergone a } \\
\text { cognitive screening }\end{array}$ & 140 & $\begin{array}{l}\text { Health care staff } \\
\text { (workflow) }\end{array}$ & $\begin{array}{l}\text { Lack of active follow-up with } \\
\text { ACP, after cognitive screening }\end{array}$ \\
\hline Menon et al. [17] & 2018 & Qualitative & $\begin{array}{l}15 \text { doctors, } 13 \text { nurses, } \\
5 \text { medical social } \\
\text { workers, } 15 \text { patients, } \\
\text { and } 13 \text { caregivers, } \\
\text { from multiple health } \\
\text { care settings across } \\
\text { Singapore. }\end{array}$ & 61 & $\begin{array}{l}\text { Health care staff } \\
\text { (attitudinal } \\
\text { and lack of } \\
\text { information) }\end{array}$ & $\begin{array}{l}\text { The subjects were confused } \\
\text { about the legal framework } \\
\text { for health care decision- } \\
\text { making. They did not find ACP } \\
\text { to be useful because family } \\
\text { members, rather than the } \\
\text { patient, were usually the key } \\
\text { decision makers. }\end{array}$ \\
\hline $\begin{array}{l}\text { Pereira-Salgado et } \\
\text { al. [12] }\end{array}$ & 2017 & Qualitative & $\begin{array}{c}\text { Religious leaders } \\
\text { from Christian and six } \\
\text { non-Christian (Jewish, } \\
\text { Buddhist, Islamic, } \\
\text { Hindu, Sikh, Bahá'í) } \\
\text { faith }\end{array}$ & $3 S$ & $\begin{array}{l}\text { Health care staff } \\
\text { (attitudinal) }\end{array}$ & $\begin{array}{l}\text { Patient's references for end-of- } \\
\text { life care reflected family and } \\
\text { geographical origins, cultural } \\
\text { traditions, personal attitudes, } \\
\text { and religiosity and faith } \\
\text { interpretations. } \\
\text { Healthcare professionals } \\
\text { should avoid generalisations } \\
\text { and be sensitive to the } \\
\text { influence of the patient's faith } \\
\text { towards end-of-life decisions. }\end{array}$ \\
\hline
\end{tabular}




\begin{tabular}{|c|c|c|c|c|c|c|}
\hline Lo et al. [18] & 2016 & $\begin{array}{l}\text { Prospective } \\
\text { cohort study }\end{array}$ & $\begin{array}{l}\text { Patients with early } \\
\text { cognitive impairment } \\
\text { [ECI] at a memory } \\
\text { clinic }\end{array}$ & 158 & $\begin{array}{l}\text { Patient } \\
\text { Social-cultural } \\
\text { Healthcare staff }\end{array}$ & $\begin{array}{l}\text { Patient factors: Limited } \\
\text { understanding of ACP } \\
\text { (education) } \\
\text { Family factors: Lack of family } \\
\text { support, family-oriented } \\
\text { decision making, reluctance } \\
\text { to discuss end-of-life issues } \\
\text { (cultural taboo) } \\
\text { Healthcare: Lapses in } \\
\text { operational process } \\
\text {-inadequate communication } \\
\text { between care team members }\end{array}$ \\
\hline Tan et al. [19] & $\begin{array}{l}2015 \text { (study } \\
\text { conducted in } \\
\text { 2012) }\end{array}$ & Descriptive & $\begin{array}{l}\text { Catholic nuns from the } \\
\text { Canossian congregation } \\
\text { in Singapore }\end{array}$ & 23 & Social-cultural & $\begin{array}{l}\text { Religion: Nuns understood } \\
\text { and accepted the usefulness } \\
\text { of ACP }\end{array}$ \\
\hline Tay et al. [20] & 2015 & Cross-sectional & $\begin{array}{l}\text { Patients with ECI at a } \\
\text { memory clinic }\end{array}$ & 98 & $\begin{array}{c}\text { Patient } \\
\text { Social-cultural }\end{array}$ & $\begin{array}{c}\text { Dependence on family for } \\
\text { decision-making (Asian } \\
\text { culture) }\end{array}$ \\
\hline Cheong et al. [21] & 2014 & Cross-sectional & $\begin{array}{l}\text { Patients with ECI at a } \\
\text { memory clinic }\end{array}$ & 93 & $\begin{array}{l}\text { Patient Social- } \\
\text { cultural }\end{array}$ & $\begin{array}{c}\text { Patient: Acceptance, } \\
\text { perception as unnecessary } \\
\text { or irrelevant, avoidance and } \\
\text { denial } \\
\text { Social-cultural: Lack of family } \\
\text { support, leave decision- } \\
\text { making to children } \\
\text { Religion not significantly } \\
\text { associated with willingness to } \\
\text { discuss ACP }\end{array}$ \\
\hline Sim et al. $[22]^{\mathrm{i}}$ & 2013 & Cross- sectional & $\begin{array}{l}\text { Patients from a heart } \\
\text { failure clinic }\end{array}$ & 58 & $\begin{array}{l}\text { Patient } \\
\text { Social-cultural } \\
\text { Healthcare staff }\end{array}$ & $\begin{array}{c}\text { Low awareness } \\
\text { Ethnicity: Malays are less } \\
\text { willing to discuss ACP } \\
\text { coordination across } \\
\text { disciplines }\end{array}$ \\
\hline Ng et al. [23] ii & 2013 & Qualitative & $\begin{array}{l}\text { Patients from Tan Tock } \\
\text { Seng Hospital }\end{array}$ & Not specified & Patient & $\begin{array}{l}\text { High awareness of ACP during } \\
\text { readmission }\end{array}$ \\
\hline Chong et al. [24] iii & 2012 & Qualitative & $\begin{array}{l}\text { Patients from Tan Tock } \\
\text { Seng Hospital }\end{array}$ & 12 & $\begin{array}{l}\text { Patient Healthcare } \\
\text { staff }\end{array}$ & $\begin{array}{l}\text { Low awareness among public } \\
\text { and healthcare professionals } \\
\text { Need for clear workflows } \\
\text { and co-ordination across } \\
\text { disciplines }\end{array}$ \\
\hline Ng et al. [25] & 2012 & Qualitative & $\begin{array}{l}\text { Family caregivers of } \\
\text { patients within the } \\
\text { palliative care unit in } \\
\text { Tan Tock Seng Hospital } \\
\text { and Dover Park } \\
\text { Hospice }\end{array}$ & 18 & $\begin{array}{l}\text { Patient Social- } \\
\text { cultural }\end{array}$ & $\begin{array}{l}\text { Low awareness, reluctance to } \\
\text { talk about planning for remote } \\
\text { and uncertain future, difficulty } \\
\text { in broaching subject, cultural } \\
\text { taboo and religious aversion }\end{array}$ \\
\hline Yee et al. [26] & 2011 & Cross-sectional & $\begin{array}{c}\text { Physicians, nurses, } \\
\text { medical social workers, } \\
\text { and other allied health } \\
\text { professionals in rental } \\
\text { units }\end{array}$ & 562 & Healthcare staff & $\begin{array}{c}\text { Only } 37.1 \% \text { of nurses viewed } \\
\text { conducting ACP discussions as } \\
\text { part of their job. } \\
\text { Nurses: Lacked confidence } \\
\text { Doctors: Time constraints, } \\
\text { concerns about family } \\
\text { backlash, perception that } \\
\text { patients were not prepared }\end{array}$ \\
\hline Ng et al. [27] & 2011 & Qualitative & $\begin{array}{c}\text { Residents in nursing } \\
\text { homes and their family } \\
\text { members }\end{array}$ & Not specified & Patient & Lack of awareness \\
\hline
\end{tabular}

\section{Findings}

The search criteria above yielded a total of 2297 articles. After removing duplicates, based on title, abstract and article review, we short-listed 13 articles for inclusion. The studies that we identified were mainly qualitative studies. Three of them were cross-sectional, one was on prospective cohort, and the remaining nine were descriptive in nature. 10 of the studies were published in journals, while the other three studies were from Advance Care 
Planning and End of Life Care (ACPEL) conference oral and poster presentations. our study had categorized the challenges broadly into patient-related factors, social-cultural factors, and health care professional-related factors (Table 2).

Table 2: Themes, Sub-themes, and Recommendations to Overcome Barriers to ACP.

\begin{tabular}{|c|c|c|}
\hline Theme & Sub-theme & Recommendation \\
\hline Patient-related factors & $\begin{array}{l}\text { Low awareness } \\
\text { (Low awareness was the most common patient factor, being } \\
\text { mentioned in } 4 \text { studies.) } \\
\text { Perception that it was unnecessary or irrelevant, Avoidance } \\
\text { or denial, } \\
\text { Limited understanding of ACP and executive function }\end{array}$ & $\begin{array}{l}\text { Need to increase awareness and provide } \\
\text { information on ACP. } \\
\text { Patients should be given adequate information } \\
\text { to weigh between the pros and cons and make } \\
\text { informed decisions about their care preferences. }\end{array}$ \\
\hline Social-cultural factors & $\begin{array}{c}\text { Lack of family support } \\
\text { Family-oriented decision-making } \\
\text { Cultural aversion towards discussing end-of-life issues } \\
\text { Difficulty in broaching the topic, religion, ethnicity. }\end{array}$ & $\begin{array}{l}\text { Supplement existing ACP questions with vignettes } \\
\text { and initiate ACP using third person perspective }\end{array}$ \\
\hline $\begin{array}{l}\text { Health care professionals-related } \\
\text { factors }\end{array}$ & $\begin{array}{l}\text { Negative attitudes towards ACP (did not see the value in } \\
\text { doing ACP with patients) } \\
\text { Lack of follow-up with patients } \\
\text { Limitations of health care professionals (time constraints, } \\
\text { concerns over family backlash, perceptions that patients } \\
\text { were not prepared, lack of confidence towards ACP } \\
\text { discussions) }\end{array}$ & $\begin{array}{l}\text { ACP could be initiated after cognitive screening } \\
\qquad[16] \\
\text { Other non-health care professionals such as } \\
\text { religious leaders and social workers can be } \\
\text { trained to administer ACP in community settings } \\
{[12,13,14]}\end{array}$ \\
\hline
\end{tabular}

\section{Discussion}

Although low awareness among the patients was the most frequently highlighted challenge overall, it appeared that this factor was a major challenge mostly in the earlier years up till 2013. The four reports which listed low awareness as a challenge were from 2013 and earlier [22-25]. Reports after 2013 did not highlight this as a challenge. Indeed, a study by Tan Tock Seng Hospital (TTSH) presented in 2013 had already reported that there was a high awareness of ACP during readmission [23]. It could be that lack of awareness no longer showed up as a significant factor in the latter studies, or that researchers concentrated on other factors which were more salient since then. This trend suggested that the efforts by government and health care institutions to promote public awareness of ACP had been successful. On the other hand, the next two commonly cited patient factors - education and perception that ACP was unnecessary, were present even in the latest study published in 2016. However, the studies that mentioned these two factors were all conducted on patients with ECI, so we need to exercise caution before generalizing this to the wider patient population [18,20,21]. At present, it seemed that social-cultural factors revolving around the family remain the biggest challenges to take-up of ACP locally. In the Asian cultural context, family involvement as a major challenge for ACP has previously been reported in studies on other Asian populations [26-29].

In Singapore, the Asian emphasis on collective decision-making leads to the propensity by patients to leave decision-making about end-of-life issues to their children, and was cited in three studies [18, $20,21]$. According to the study by Tay (2015) [20] issues pertaining to the Asian culture of collective family decision-making were the greatest barriers to ACP engagement. Lo's (2016) [18] study on patients with ECI showed that the unmarried patients were more likely to actualize ACP plans compared to married patients; it was likely the latter would tend to defer decision-making on end-oflife issues to family members. Another major Asian cultural factor was the aversion towards talking about death for fear that it would bring bad luck, mentioned in two reports $[18,23]$. Lack of family support for ACP was another social-cultural factor. Cheong et.al [21] categorized this lack of support into the following: patient's lack of trust in the family, family agreeing with patient that ACP was irrelevant, and family members' dismissive attitude towards patients' end-of-life plans [21].

However the effect of religion and ethnicity on the Singapore population is unclear. In a focus group discussion by Tan et.al (2017) [19] with 23 Catholic nuns, 18 of the nuns (78\%) responded that ACP was not against their religious beliefs. In the descriptive study by Ng (2013) [13], one participant expressed an objection towards ACP on the basis of her Catholic belief [23]. Viewing these two studies together, it might be reasonable to conclude that while the religious leaders are not against the concept of ACP, it is unclear whether this opinion is shared by the rank-and-file religious followers. A third study had ambivalent outcome with regard to religion; although the theme of leaving the future to God cropped up, the study did not find any significant association between religion and willingness to engage in ACP discussion [21]. Ethnicity was mentioned as a challenge in a pilot study conducted on Singapore patients from a heart failure clinic [22]. This study 
showed that Malays were less likely to discuss ACP compared to other ethnic groups. We can compare this finding against that from an earlier Malaysian study which revealed that race, ethnicity, and cultural values were important factors in ACP. The majority of the Malaysian subjects, especially those with Islamic faith, believed that their views were influenced by religion [30]. For the Singapore population, while the results thus far appear mixed, it is reasonable to conclude that views towards ACP might be split along religious and ethnic lines. More local research is needed to shed light into this.

Another major aspect of challenges to ACP is the lapse in communications and co-ordination among health care members, and this is a problem that has remained persistent. A study in 2016 revealed that lapses in operational processes mainly due to inadequate communication within the team played a significant role in low ACP completion [18]. Two other earlier studies also identified inadequate coordination across multiple disciplines as a major challenge [22,24]. In addition, health care workers' individual competencies were flagged out as a major challenge in the early years. A 2011 study on the knowledge, attitudes and experience of renal health care providers towards ACP showed that only $37.1 \%$ of nurses considered ACP discussion as part of their role, and that nurses were the least confident in conducting ACP discussions [26]. Doctors fared better, but still, the study identified several barriers faced by physicians - fear of upsetting the family, lack of time, and the perception that patients were not ready to discuss ACP. Since 2011, the AIC has been training health care personnel in ACP facilitation skills $[3,31]$ and it is likely that health care personnel are now better equipped to facilitate ACP discussions, although there is no recent study to assess the current state of competency.

\section{The Dynamic Value-based Approach to Advance Care Planning}

Following the findings from this literature review, this study proposed the use of vignettes to elucidate values and principles of the patient, in addition to existing ACP methods. Vignettes are "short stories about hypothetical characters in specified circumstances, to which the interviewee is invited to respond" [32]. The use of fictitious but popular scenarios that are culturally adapted provides realism that enables the patient to relate to, and suss out their values and principles behind their expressed preferences. The use of third person perspective also allows family members and professionals to circumvent the issue of broaching sensitive topics. For instance, traditional Chinese seniors may find it inauspicious to talk about death and dying. Using vignettes will enhance the ability for realism and more accurately reflecting patient's preferences in scenarios that present dilemmas and limitations to the implementation of their preferred care and medical arrangements. This study has drafted the vignettes in (Table 3). as samples for adaptation and application, to overcome social-cultural barriers in initiating ACP.

Table 3: Samples of Vignettes to Understand Patient's Values, Preferences and Priorities.

\section{Vignette}

Mrs Tan, who is 83-year old has mobility issues. She also struggles with bathing, toileting and feeding herself. She prefers receiving care at her own home but is worried that she might burden her family. She is not keen to stay in the nursing home. Her family intends to either let Mrs Tan attend a day care centre nearby or employ a foreign domestic helper to take care of her. Mrs Tan's family finds the cost of her care to be high but can manage. In your opinion, how can Mrs Tan be ideally taken care of? Why?

Mr Lim who is 79-years old has dementia. He is often forgetful and faces other issues such as difficulties in controlling his bowels and difficulties in swallowing food. His doctor suggested tube-feeding to minimise the risk of chest infection. He is not keen on tubefeeding, so he takes purée. He often loses his appetite and wants to eat normal food. If you were Mr Lim, would you have chosen to tube-feeding or purée food? Why?

Mr Lim's family also wanted to appoint a family member to manage his monetary affairs, should he lose the mental capacity to do so. However, Mr Lim misunderstood his family's intention and accused them of being greedy. He insisted that his monetary affairs be managed by his wife, who is also aged and in poor health. If this was the scenario you were faced with, would you have preferred your finances to be managed by your spouse or other family members? Or how would you have liked your finances to be managed, if you are unable to do so? Why?

Miss Siti is a 90-year old single lady who lives near her beloved nieces and nephews. Even though she has no children of her own, her nieces and nephews have promised to look after her when she is unable to do so. Miss Siti's legs are weak and after the recent two episodes of fall, she decided that it is no longer safe for her to live alone. She considered living with her nieces and nephews but realised that it may not be ideal. Most of her nieces and nephews are married, have young children to look after and some of their spouses did not appear very welcoming towards Miss Siti. The rest of the nieces and nephews who are single have very busy work life and are usually home late. Miss Siti is uncertain of whether she should employ a foreign domestic helper to look after her, shift to live with her nieces and nephews or look for alternative care arrangements at institutions. She likes her freedom but is also aware that the nursing home is best equipped to look after her. She is also concerned that the foreign domestic helper might not be committed to look after her and she is not used to having a non-family member living in her house. What would your advice Miss Siti to do? Why?
Prioritising Patient's Competing Preferences

This vignette presents the issue of personal preference at the expense of the family's convenience and resources. It aims to understand the patient's preference when faced with competing interests. Patient wants to age at home and be near to family members, but this care arrangement may burden the family in terms of care arrangements and cost.

This vignette presents the dilemma of balancing between health concerns and personal enjoyment. It aims to understand how the patient would like to strike a balance between enjoyment and health care.

This vignette presents the issue of distrust and the need for someone to assist in financial management and decision. It aims to ease the patient into a discussion on finances, financial management and identify trusted individuals for patient's financial affairs.

This vignette presents the issue of lack of familial support It aims to understand the patient's preferred care arrangement in the absence of familial support. 
Madam Puvan is an 80-year old lady with heart issues. Her doctor advised her that she may not have a good quality of life in the event that her heart fails, and she chooses to be resuscitated. Her doctor also advised her that in the event that she may slip into coma and requires life support, she has a choice to receive life support but will likely not enjoy a good quality of life even if she regains consciousness. In your opinion, should Madam Puvan opt for resuscitation and/or life support? Why?

Mr Ibrahim is 78-year old and suffers from advance stage lung cancer. His doctor advised that he may be able to prolong his life if he attempts treatment. However, Mr Ibrahim may experience pain and discomfort from the treatment, and it is uncertain how successful the treatment will be. Mr Ibrahim decided that it is more important for him to enjoy his remaining time than to try to prolong his life and possibly suffer from both the illness and the treatment. Do you have the same thinking as Mr Ibrahim? Why?
This vignette presents the choice between quality of life and quantity of life. It aims to understand whether the patient will prioritise quality of life or extended life with less quality. It also aims to know patient's preference for resuscitation and life support

This vignette also presents the choice between quality of life and quantity of life. It aims to identify the point in which the patient prioritises quality of life over treatment.

\section{Limitations}

The biggest drawbacks to the studies used in this review were the small sample sizes and the limitation of the sampled populations to specific types of patients, which makes it hard to generalize the findings. Only two studies had $n>100$ (Yee, 2011) [5]. Most of the other studies were conducted on specific types of patients (patients from a memory clinic in the case of Lo, Tay, and Cheong [18,20,21] the palliative care unit for Ng's [25] study, health professionals in rental units for Yee [13], heart failure clinic for Sim (2013) [33]. In fact, three of the studies - almost one-third of studies in this review - used patients with ECI $[18,20,21]$, so this population segment might be overrepresented in our review. All the 13 studies cited were largely qualitative studies; only four of them carried out further quantitative analysis to discern associations between the variables and ACP take-up [18,20,21,26].

\section{Recommendations}

This study recommends for a large-scale mixed research study across various health care and non-health care settings to evaluate the relevance and usefulness of the value-based approach in complementing existing ACP questions. Areas to evaluate would be the cultural fit between the scenarios and issues presented in the vignettes and the Singapore population, the ease of conducting ACP with vignettes, the extent of usefulness in complementing existing ACP questions with vignettes, the impact of findings from vignettes in assisting the patients' family members in making decisions when faced with ambiguity or dilemmas, the ease and challenges in using vignettes and areas to improve. The reliability of the vignettes could also be evaluated in future studies by applying different vignettes that test for similar values, to assess if the patient's values are consistent. The validity of the vignettes approach could be strengthened with repetitive usage of different characters and scenarios on the same patient so as to identify and understand changes in values over time.

\section{Conclusion}

The government's public education efforts appeared to have increased awareness of ACP issues among the public. Currently, social-cultural factors such as the involvement of the family in the decision-making process, cultural aversion towards talking about death, and lack of family support, appear to be the most significant factors which impeded the take-up of ACP. The use of vignettes is believed to circumvent the issue of cultural sensitivities by using fictitious characters and conversing with the patient using a thirdperson perspective. It is crucial that the administration of ACP and the vignettes is supported by giving adequate information for patients and caregivers to weigh between the advantages and disadvantages of the various options. For instance, the concepts of "qualitative medical futility" and "quantitative medical futility" are underlying key values in treatment preferences. Patients need to understand these concepts and make informed ACP decisions towards topics such as "preference for" and "when to" withhold and/or withdraw treatment, be placed on life-support, activate the do-not-resuscitate order and euthanasia [33].

The administration of ACP should not be a one-off affair. The dynamic value-based approach encourages ongoing discourse on $\mathrm{ACP}$, as patient's values may change over time and as the health conditions deteriorates. Revisiting the preferences that patients have earlier indicated will also offer them opportunities to reflect and be more certain of their preferences. An ongoing discourse may also lead to deeper discussion and open up opportunities for emotional support to the patient. The vignettes are believed to facilitate ACP conversations and surface patient's concerns and fears. Patients are then encouraged to indicate preferences that are more reflective and valid, especially when preferences conflict or when family members are faced with dilemmas.

\section{References}

1. (2010) NMEC, Guide for Healthcare Professionals on The Ethical Handling of Communication in Advance Care Planning.

2. Tay M, SE Chia, J Sng (2010) Knowledge, attitudes, and practices of the Advance Medical irective in a residential estate in Singapore. Ann Acad Med Singapore 39(6): 424-428.

3. Koh SF (2015) As population ages, more are confronting the last taboo.

4. (2015) MOH, End-of-life issues (MOH Parliamentary Q\&A).

5. Jimenez G, Tan WS, Virk AK, Low CK, Car J, et al. (2018) Overview of Systematic Reviews of Advance Care Planning: Summary of Evidence and Global Lessons. J Pain Symptom Manage 56(3): 436-459.e25.

6. Jimenez G, Tan WS, Virk AK, Low CK, Car J, et al. (2018) State of advance care planning research: A descriptive overview of systematic reviews. Palliat Support Care p. 1-11.

7. Fahner JC, Beunders AJM, van der Heide A, Judith A C Rietjens, Maaike M Vanderschuren, et al. (2019) Interventions Guiding Advance Care Planning Conversations: A Systematic Review. J Am Med Dir Assoc 20(3): 227-248 
8. Kermel Schiffman I, Werner P (2017) Knowledge regarding advance care planning: A systematic review. Arch Gerontol Geriatr 73: 133-142.

9. Cheng HWB (2018) Advance Care Planning in Chinese Seniors: Cultural Perspectives. J Palliat Care 33(4): 242-246.

10. Mc Dermott E, Selman LE (2018) Cultural Factors Influencing Advance Care Planning in Progressive, Incurable Disease: A Systematic Review with Narrative Synthesis. J Pain Symptom Manage 56(4): 613-636.

11. Ohr S, Jeong S, Saul P (2017) Cultural and religious beliefs and values, and their impact on preferences for end-of-life care among four ethnic groups of community-dwelling older persons. J Clin Nurs 26(11-12): 1681-1689.

12. Pereira Salgado A, Mader P, O’Callaghan C, Boyd L, Staples M (2017) Religious leaders' perceptions of advance care planning: A secondary analysis of interviews with Buddhist, Christian, Hindu, Islamic, Jewish, Sikh and Bahá'í leaders. BMC Palliat Care 16(1): 79.

13. Chu D, Yen YF, Hu HY, Yun Ju Lai, Wen Jung Sun, et al. (2018) Factors associated with advance directives completion among patients with advance care planning communication in Taipei, Taiwan. PLoS One 13(7): e0197552.

14. Wang CW, Chan CLW, Chow AYM (2017) Social workers' involvement in advance care planning: A systematic narrative review. BMC Palliat Care 17(1): 5 .

15. Michael N, O'Callaghan C, Sayers E (2017) Managing 'shades of grey': A focus group study exploring community-dwellers' views on advance care planning in older people. BMC Palliat Care 16(1): 2.

16. Lee JJY, Barlas J, Thompson CL, Dong YH (2018) Caregivers' Experience of Decision-Making regarding Diagnostic Assessment following Cognitive Screening of Older Adults. Journal of Aging Research pp. 8352816.

17. Menon S, Kars MC, Malhotra C, Campbell AV, van Delden JJM (2018) Advance Care Planning in a Multicultural Family Centric Community: A Qualitative Study of Health Care Professionals', Patients', and Caregivers' Perspectives. J Pain Symptom Manage 56(2): 213-221.e4.

18. Lo TJ, Ha NH, Ng CJ, Tan G, Koh HM, et al. (2017) Unmarried patients with early cognitive impairment are more likely than their married counterparts to complete advance care plans. Int Psychogeriatr 29(3) 509-516.

19. Tan L, Sim LK, Ng L, Toh HJ, Low JA (2017) Advance Care Planning: The Attitudes and Views of a Group of Catholic Nuns in Singapore. American Journal of Hospice and Palliative Medicine® 34(1): 26-33.

20. Tay SY (2015) Education and Executive Function Mediate Engagement in Advance Care Planning in Early Cognitive Impairment. J Am Med Dir Assoc 16(11): 957-962.

\section{ISSN: 2574-1241}

DOI: 10.26717/BJSTR.2020.31.005116

Amberyce Ang. Biomed J Sci \& Tech Res

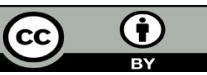

This work is licensed under Creative

Commons Attribution 4.0 License

Submission Link: https://biomedres.us/submit-manuscript.php
21. Cheong K, Fisher P, Goh J, Ng L, Koh HM, et al. (2015) Advance care planning in people with early cognitive impairment. BMJ Support Palliat Care 5(1): 63-69.

22. Sim DK (2013) Advance Care Planning for Patients with Heart Failure in a Multi-ethnic South East Asian Cohort. BMJ supportive \& palliative care 3(2): 257-258.

23. Ng R, Chan S, Ng TW, Chiam AL, Lim (2013) Starting Pilots in Advance Care Planning in a Tertiary Hospital in Singapore. BMJ Support Palliat Care 3(2): 279-279.

24. Chong R (2012) Sowing seeds and building collaborations: Challenges faced and learning points in starting systematic advance care planning in a tertiary hospital in Singapore. BMJ supportive \& palliative care 2(2): 201-202.

25. Ng R, Chan S, Ng TW, Chiam AL, Lim S (2013) An exploratory study of the knowledge, attitudes, and perceptions of advance care planning in family caregivers of patients with advanced illness in Singapore. BMJ Support Palliat Care 3(3): 343-348.

26. Yee A, Seow YY, Tan SH, Goh C, Qu L, et al. (2011) What do renal healthcare professionals in Singapore think of advance care planning for patients with end-stage renal disease? Nephrology (Carlton) 16(2): 232-238.

27. Wee NT, SC Weng, LLE Huat (2011) Advance care planning with residents in nursing homes in Singapore. Asia Pacific Journal of Social Work and Development 21(1): 97-104.

28. Kwak J, Salmon JR (2007) Attitudes and preferences of Korean American older adults and caregivers on end-of-life care. J Am Geriatr Soc 55(11): 1867-1872.

29. Bowman KW, Singer PA (2001) Chinese seniors' perspectives on end-oflife decisions. Soc Sci Med 53(4): 455-464.

30. Htut Y, Shahrul K, Poi PJ (2007) The views of older Malaysians on advanced directive and advanced care planning: A qualitative study. Asia Pac J Public Health 19(3): 58-67.

31. Chung I (2013) Implementing a national advance care planning (ACP) program in Singapore. BMJ supportive \& palliative care 3(2): 256-257.

32. Finch J (1987) The Vignette Technique in Survey Research. Sociology 21(1): 105-114.

33. Low JA, Ho E (2017) Managing Ethical Dilemmas in End-Stage Neurodegenerative Diseases. Geriatrics (Basel) 2(1): 8

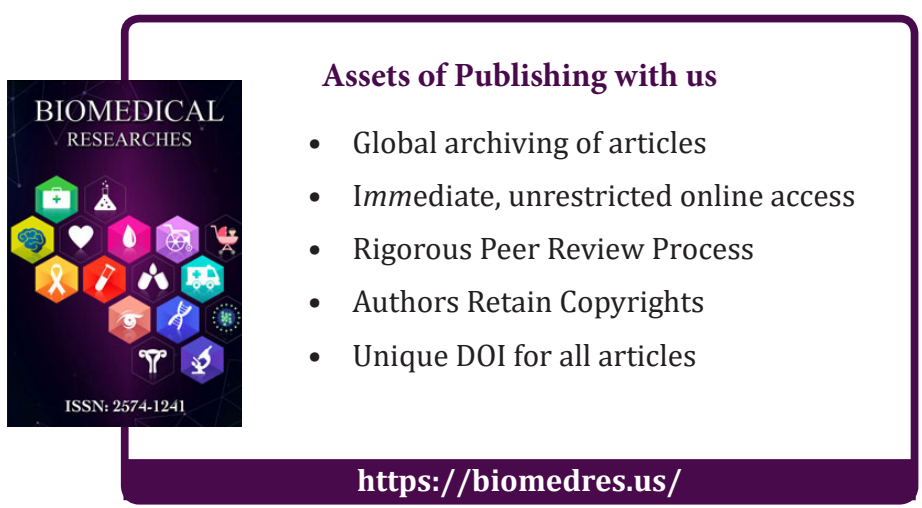

